\title{
Enhancing Endocannabinoid Neurotransmission Augments The Efficacy of Extinction Training and Ameliorates Traumatic Stress-Induced Behavioral Alterations in Rats
}

\author{
Maria Morena ${ }^{1,4,5}$, Andrea Berardi ${ }^{1,4}$, Paola Colucci', Maura Palmery', Viviana Trezza ${ }^{2}$, Matthew N Hill ${ }^{3}$ and \\ Patrizia Campolongo*,I \\ 'Department of Physiology and Pharmacology, Sapienza University of Rome, Rome, Italy; ${ }^{2}$ Department of Science, Section of Biomedical Sciences \\ and Technologies, University Roma Tre, Rome, Italy; ${ }^{3}$ Hotchkiss Brain Institute, Departments of Cell Biology \& Anatomy and Psychiatry, University of \\ Calgary, Calgary, Canada
}

\begin{abstract}
Exposure to a traumatic event may result in the development of post-traumatic stress disorder (PTSD). Endocannabinoids are crucial modulators of the stress response, interfere with excessive retrieval and facilitate the extinction of traumatic memories. Exposure therapy, combined with pharmacotherapy, represents a promising tool for PTSD treatment. We investigated whether pharmacological manipulations of the endocannabinoid system during extinction learning ameliorates the behavioral changes induced by trauma exposure. Rats were exposed to inescapable footshocks paired with social isolation, a risk factor for PTSD. One week after trauma, rats were subjected to three spaced extinction sessions, mimicking human exposure therapy. The anandamide hydrolysis inhibitor URB597, the 2arachidonoylglycerol hydrolysis inhibitor JZLI84 or the cannabinoid agonist WIN55,212-2 were administered before or after the extinction sessions. Rats were tested for extinction retention 16 or 36 days after trauma and 24-h later for social interaction. Extinction training alone reduced fear of the trauma-associated context but did not restore normal social interaction. Traumatized animals not exposed to extinction sessions exhibited reductions in hippocampal anandamide content with respect to home-cage controls. Noteworthy, all drugs exerted beneficial effects, but URB597 $(0.1 \mathrm{mg} / \mathrm{kg})$ induced the best improvements by enhancing extinction consolidation and restoring normal social behavior in traumatized rats through indirect activation of CBI receptors. The ameliorating effects remained stable long after treatment and trauma exposure. Our findings suggest that drugs potentiating endocannabinoid neurotransmission may represent promising tools when combined to exposure-based psychotherapies in the treatment of PTSD.
\end{abstract}

Neuropsychopharmacology (20 I8) 43, I284-1296; doi:I0.1038/npp.20 I7.305; published online 24 January 2018

\section{INTRODUCTION}

Post-traumatic stress disorder (PTSD) is a chronic psychiatric disease of high prevalence and morbidity. It develops in vulnerable subjects after experiencing an intense and lifethreatening traumatic event. The disorder is listed in the fifth edition of the Diagnostic and Statistical Manual of Mental Disorders (DSM-5) as a 'trauma and stressor-related disorder' (American Psychiatric Association, 2013). Symptomatic features of PTSD include both cognitive and emotional alterations, primarily caused by an aberrant adaptation to the trauma (American Psychiatric Association, 2013). Cognitive

* Correspondence: Professor P Campolongo, Department of Physiology and Pharmacology Sapienza, University of Rome, P.le A. Moro 5, Rome 00185, Italy, Tel: +396 49912450, Fax: +396 499|2480, E-mail: patrizia.campolongo@uniromal.it

${ }^{4}$ These authors contributed equally to this work.

${ }^{5}$ Current address: Hotchkiss Brain Institute, Departments of Cell Biology \& Anatomy and Psychiatry, University of Calgary, T2N 4NI Calgary, Canada.

Received 4 May 2017; revised 9 December 2017; accepted 15 December 2017; accepted article preview online 21 December 2017 symptoms include the inability to extinguish fear and anxiety responses, to suppress episodic memory retrieval and to acquire safety signals (Holmes and Singewald, 2013; Moore, 2009). Cognitive dysfunctions are linked to both PTSD development and chronicity and are strictly related to mnestic symptoms, which include spontaneous recollections, flashbacks, and dissociative amnesia (Moore, 2009; Parsons and Ressler, 2013). The marked changes in reactivity, arousal, mood, and anxiety (Heim and Nemeroff, 2009) complete the symptomatological picture, causing severe impairments in patient's global functioning, which include reduced interest in social contact (American Psychiatric Association, 2013). The gold standard pharmacotherapy is represented by selective serotonin re-uptake inhibitors. However, the efficacy of these drugs is far from being satisfactory (Hoskins et al, 2015). Cognitive behavioral exposure-based psychotherapy, which is believed to engage extinction learning processes, in some cases represents an effective PTSD treatment (Abramowitz, 2013; Furini et al, 2014; Milad and Quirk, 2012). This therapeutic approach is based on the repeated exposure of the patient to trauma-related 
reminders, in a safe controlled situation, thus lacking the negative consequences for the subject (Abramowitz, 2013). Even if exposure therapy has proven some degree of efficacy in treating PTSD (Bisson et al, 2013), drop outs are frequent among patients reaching rates of $39 \%$ of the population (Gutner et al, 2016). Moreover, PTSD symptoms can relapse when the exposure therapy ends leading to fear reinstatement. Therefore, it appears worth to investigate if drugs interfering with the excessive retrieval or enhancing the extinction of the traumatic memory could improve the efficacy of exposure therapy by preventing spontaneous recovery (Choi et al, 2010; Hofmann, 2007; McGuire et al, 2014; de Quervain et al, 2011; Singewald et al, 2015; Trezza and Campolongo, 2013).

High attention in this regard has been lately given to drugs potentiating the endocannabinoid signaling (Campolongo et al, 2013; Morena and Campolongo, 2014; Rabinak and Phan, 2014; Trezza and Campolongo, 2013). The endocannabinoid system is composed by the cannabinoid receptors type 1 (CB1) and type 2 (CB2), two principal endogenous ligands, namely $\mathrm{N}$-arachidonoyl ethanolamine (anandamide, AEA) and 2-arachidonoyl glycerol (2-AG) (Kano et al, 2009; Di Marzo, 1999), and their primarily degrading enzymes the fatty-acid amide hydrolase (FAAH) (Cravatt et al, 1996) and the monoacylglycerol lipase (MAGL) (Dinh et al, 2002), for AEA and 2-AG, respectively. The endocannabinoid system can be exogenously targeted by means of the FAAH inhibitor URB597 that elevates endogenous levels of AEA (Kathuria et al, 2003), of the MAGL inhibitor JZL184 that elevates endogenous levels of 2-AG (Long et al, 2009; Morena et al, 2015) or by direct cannabinoid receptor agonists, such as WIN55,212-2. Genetic deletion or pharmacological blockade of CB1 receptors in rodents result in impaired fear memory extinction (Chhatwal et al, 2005; Marsicano et al, 2002; Morena and Campolongo, 2014; Pamplona et al, 2008). Consistently, cannabinoid agonists enhance extinction (Bitencourt et al, 2014; Bowers and Ressler, 2015; GunduzCinar et al, 2013; Pamplona et al, 2008) and attenuate retrieval of aversive memory (Atsak et al, 2012; Morena et al, 2015; Morena and Campolongo, 2014).

We recently proposed a footshock-based paradigm able to mimic both the enduring cognitive and emotional facets of PTSD pathology useful to model the extinction-based exposure therapy combined with pharmacological treatment (Berardi et al, 2014). The main purpose of the present study was to evaluate the effects of pharmacological manipulation of the endocannabinoid system in a preclinical model of PTSD, by targeting extinction learning processes. To this aim, we first adapted our model (Berardi et al, 2014) by including multiple extinction sessions and we verified whether the extinction procedure alone was able to improve the behavioral alterations displayed by traumatized rats. We also evaluated the effects induced by trauma exposure on AEA and 2-AG levels in brain regions critically involved in extinction and emotional behavior, ie, hippocampus, prefrontal cortex, and amygdala (Furini et al, 2014). We then evaluated whether activation of the endocannabinoid system, by facilitating extinction and dampening the retrieval of fear memory, could ameliorate the efficacy of 'extinction-based exposure therapy', leading to improvements that remain stable long after trauma exposure and pharmacological treatment termination.

\section{MATERIALS AND METHODS}

\section{Subjects}

Male Sprague-Dawley rats (350-450 g at the time of testing; Charles River Laboratories, Calco, Italy) were kept in an airconditioned room (temperature: $21^{\circ} \pm 1^{\circ} \mathrm{C}$; lights on 7:00 a. m.-7:00 p.m.) with food and water available $a b$ libitum. All the experiments were performed during the light phase of the cycle. Rats were handled for 1 min for 7 consecutive days before behavioral testing. All procedures were performed in compliance with the European Union Directive on the protection of animals used for scientific purposes (2010/63/ EU) and the Italian law (D.L. 26/2014).

\section{Behavioral Procedures}

The PTSD model we first described (Berardi et al, 2014) was adapted for the assessment of memory extinction.

The experimental apparatus consisted in a metal troughshaped alley $(60 \mathrm{~cm}$ long, $15 \mathrm{~cm}$ deep, $20 \mathrm{~cm}$ wide at the top, and $6.4 \mathrm{~cm}$ wide at the bottom) connected to an animal shocker. All the experimental sessions were video-recorded and subsequently scored by two well-trained researchers blind to the experimental conditions. After each session, fecal boli were removed and the apparatus was cleaned with a $70 \%$ ethanol solution.

Housing. All rats were individually housed for 3 days prior to the habituation session and remained singly housed until the end of the behavioral testing. We have previously shown that social isolation is necessarily required to develop enduring signs of emotional distress upon exposure to a traumatic event (Berardi et al, 2014).

Habituation. On the first day of testing (day - 1), rats were individually taken from the home-cage and habituated for $5 \mathrm{~min}$ to the test apparatus. Rats were then returned to their homecages.

Exposure session. On day 0, rats were individually placed in the apparatus and were left undisturbed for $2 \mathrm{~min}$. Then, five footshocks ( $2 \mathrm{~s}, 0.8 \mathrm{~mA})$ were randomly delivered. After the last shock, rats were kept in the apparatus for $60 \mathrm{~s}$ to facilitate context association to the aversive stimuli. A control group was only exposed to the apparatus for $10 \mathrm{~min}$ without any footshock presentation.

Extinction sessions. Each of the three extinction sessions consisted in a 10-min re-exposure to the experimental apparatus, with the first carried out 7 days after the exposure session (day 7). Each subsequent session was separated from the preceding one by a 72 -h interval (days 10, 13). A control group was not exposed to the extinction procedure.

Extinction retention test. To evaluate memory retention, rats were exposed to the experimental apparatus 16 or 36 days after trauma exposure (3 or 20 days after the last extinction session), for a 10-min period, during which contextual freezing behavior was evaluated (Chen et al, 2012; Wheeler et al, 2013). 
Social interaction test. To evaluate the level of emotional distress, rats were tested in the social interaction test (SI), which was carried out $24 \mathrm{~h}$ after the extinction retention test (day 17 or day 37 ).

Couples for the SI were established according to the following criteria: (1) belonging to the same drug treatment/ experimental condition; (2) unfamiliarity; (3) least weight difference. Each couple was put for $10 \mathrm{~min}$ in a quadrangular arena $(40 \times 40 \times 60 \mathrm{~cm})$ made of Plexiglas with clean sawdust covering the floor, under red light conditions ( $\sim 10$ lux). After each session, rats were returned to their home cage, fecal boli were removed, sawdust was blended, and the arena's walls were cleaned with a $70 \%$ ethanol solution. In this test, social behavior was scored as previously described (Berardi et al, 2014).

\section{Drugs}

The FAAH inhibitor URB597 $(0.1,0.3 \mathrm{mg} / \mathrm{kg})$, the MAGL inhibitor JZL184 $(0.5,1 \mathrm{mg} / \mathrm{kg})$, the CB agonist WIN55,212-2 $(1,3 \mathrm{mg} / \mathrm{kg})$, and the CB1 antagonist SR141716 $(1 \mathrm{mg} / \mathrm{kg})$ were dissolved in a vehicle containing 5\% polyethylene glycol, 5\% Tween 80 , and 90\% saline solution. Doses were chosen on the basis of pilot experiments performed in our laboratory and on literature data showing behavioral efficacy and lack of locomotor alterations in rats (Campolongo et al, 2013; Haller et al, 2009; Järbe et al, 2007; Manduca et al, 2016; Morena and Campolongo, 2014; Robinson et al, 2003; Sciolino et al, 2011). All drugs were freshly prepared on the day of the experiment and administered intraperitoneally at a volume of $1 \mathrm{ml} / \mathrm{kg}$. On the basis of the experimental procedure, WIN55,212-2, URB597, and JZL184 (or vehicle) were administered either $1 \mathrm{~h}$ before or immediately after each extinction session on days 7, 10, and 13 . SR141716 (or vehicle) was administered $30 \mathrm{~min}$ before the extinction sessions on days 7, 10, and 13 . In all the experiments neither drugs nor vehicle were administered on the extinction retention session on day 16 or 36. Drugs were kindly donated by the National Institute of Mental Health (Chemical Synthesis and Drug Supply Program, Bethesda, MD, USA).

\section{Endocannabinoid Extraction and Analysis}

AEA and 2-AG extraction and analysis were performed as previously described (Morena et al, 2015). In brief, animals were killed immediately after the SI test and the hippocampus, prefrontal cortex and amygdala were dissected by a welltrained experimenter. The brain areas were put into 2- $\mathrm{ml}$ Eppendorf tubes and immediately stored at $-80^{\circ} \mathrm{C}$ in order to avoid endocannabinoid degradation (Hauer et al, 2011). Brain tissue was weighed and placed into borosilicate glass culture tubes containing $2 \mathrm{ml}$ of acetonitrile with 5 pmol of $\left[{ }^{2} \mathrm{H}_{8}\right]$ AEA and $5 \mathrm{nmol}$ of $\left[{ }^{2} \mathrm{H}_{8}\right] 2-\mathrm{AG}$ for extraction, and homogenized with a glass rod. Tissue was sonicated for $30 \mathrm{~min}$ on ice water and incubated overnight at $-20^{\circ} \mathrm{C}$ to precipitate proteins, then centrifuged at $1500 \times g$ to remove particulates. The supernatants were transferred to a new glass tube and evaporated to dryness under $\mathrm{N}_{2}$ gas. The samples were reconstituted in $300 \mu \mathrm{l}$ of acetonitrile and dried again under $\mathrm{N}_{2}$ gas. Lipid extracts were suspended in $20 \mu \mathrm{l}$ of acetonitrile and stored at $-80^{\circ} \mathrm{C}$ until analysis. Analysis of
AEA and 2-AG was performed by liquid chromatography mass spectrometry analysis as previously detailed (Qi et al, 2015).

\section{Statistical Analysis}

Statistical analysis was performed using SPSS statistical software. Each measure is expressed as mean \pm SEM. For each measure on experiment 1, independent samples Student's $t$-test was performed. In the evaluation of freezing percentage across the extinction sessions, a repeated measures ANOVA was performed with sessions as the repeated factor and treatment and shock condition as between-subjects factors. In all the other cases, data were analyzed with one- or two-way ANOVA, when appropriate. Tukey-Kramer post hoc test was performed to control for significant differences between groups when appropriate. Significance was considered for $P<0.05$.

\section{RESULTS}

\section{Extinction Training Attenuates the Behavioral Alterations of Trauma-exposed Rats}

In this experiment, we examined the effects of the extinction training procedure on behavioral alterations displayed by footshock-exposed rats (Extinction group), compared with a control group never exposed to the extinction sessions (No-Extinction group). In our previous work, we showed that the exposure to a single session of multiple footshocks caused in rats a long-lasting form of traumatic memory along with a sustained reduction of social behavior when compared with unexposed control rats (Berardi et al, 2014).

Here, we found that the extinction procedure alone reduced conditioned freezing 16 days after the exposure to footshocks, but failed to promote an enhancement of social behavior. Indeed, when analyzing freezing percentage at day 16, Student's $t$-test revealed that rats receiving the full extinction protocol displayed significantly lower levels of freezing than rats never exposed to the extinction sessions ( $t_{18}=-3.57, P=0.002$ ) (Figure 1a). Conversely, for the SI time, $t$-test revealed only a trend toward significance $\left(t_{18}=1.89, P=0.075\right)$ (Figure $1 \mathrm{~b}$ ).

We next measured endocannabinoid AEA and 2-AG levels immediately after the SI test in rats subjected to the extinction sessions, in rats never exposed to the extinction sessions and in a home-cage control group, in the hippocampus, prefrontal cortex, and amygdala. In the hippocampus, ANOVA for AEA levels revealed a significant effect of condition $\left(\mathrm{F}_{2,27}=3.53, P=0.043\right)$ and post hoc tests showed that rats not exposed to the extinction procedure had significantly lower AEA levels when compared with homecage controls (Table 1). No differences were found in the hippocampus for 2-AG levels $\left(\mathrm{F}_{2,27}=0.008, \quad P=0.99\right.$, Table 1). In the prefrontal cortex, ANOVA for AEA (Table 1) and 2-AG (Table 1) levels did not reveal any significant effect of the condition $\left(\mathrm{F}_{2,24}=0.34, P=0.72\right.$; $\mathrm{F}_{2,24}=0.80, P=0.46$, respectively). Similarly, in the amygdala, ANOVA for AEA (Table 1) and 2-AG (Table 1) levels did not reveal any significant condition effect $\left(\mathrm{F}_{2,26}=0.057\right.$, $P=0.95 ; \mathrm{F}_{2,26}=0.41, P=0.67$, respectively). 
Effects of Pre-Extinction Cannabinoid Drug Administration On Trauma-Induced Behavioral Alterations

In these experiments, we investigated the effects of the tested drugs given $1 \mathrm{~h}$ before extinction training sessions, on both cognitive and emotional modification following trauma exposure. Results showed only a limited efficacy of the tested substances in modifying rats' behaviors. Indeed, the lower dose of URB597 $(0.1 \mathrm{mg} / \mathrm{kg})$ increased social behavior, and both doses of JZL184 (0.5 and $1 \mathrm{mg} / \mathrm{kg})$ reduced global freezing percentages. Concerning URB597 effects, ANOVA for freezing time across sessions showed a significant effect of sessions $\left(\mathrm{F}_{3,81}=19.45, P<0.001\right)$ but no significant effects of drug treatment and sessions $\times$ drug treatment interaction
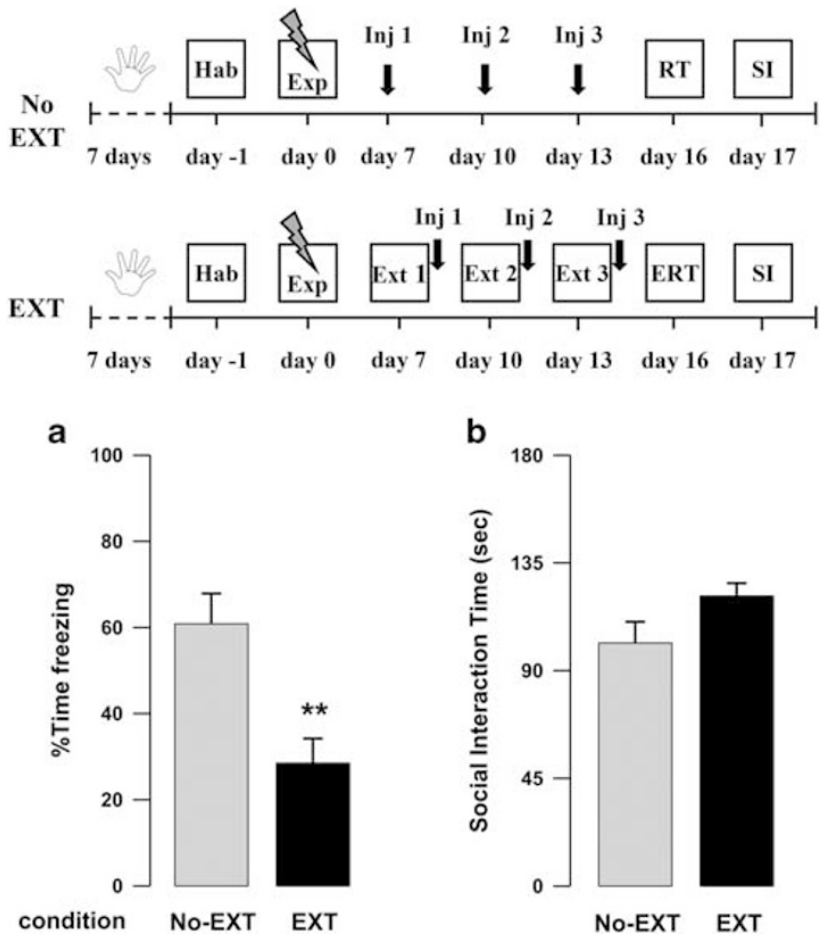

Figure I (a) Freezing rates of vehicle-treated rats exposed to the footshock experience (Exp) but not subjected to the extinction sessions (No-EXT) and of rats exposed to the extinction sessions (EXT I, 2, and 3), as assessed during the extinction retention test (ERT) or retention test (RT) on day 16. (b) Social interaction (SI) time of No-EXT and EXT rats during the $\mathrm{SI}$ test on day 17. (**P $<0.0 \mathrm{I}$ vs the No-EXT group.) Data are expressed as mean+SEM ( $n=10$ per group).
$\left(\mathrm{F}_{2,27}=0.80, \quad P=0.46 ; \quad \mathrm{F}_{6,81}=0.16, \quad P=0.99, \quad\right.$ respectively $)$ (Figure 2a). Conversely, in the SI, ANOVA showed a significant effect of drug treatment $\left(\mathrm{F}_{2,27}=6.029, P=0.007\right)$ and post hoc analysis revealed that animals treated with the $0.1 \mathrm{mg} / \mathrm{kg}$ dose spent significantly more time interacting with the social partner when compared with controls $(P<0.05)$ (Figure 2b). ANOVA for freezing time across sessions showed a significant effect of both sessions and drug treatment for JZL184 $\left(\mathrm{F}_{3,81}=42.82, P<0.001 ; \mathrm{F}_{2,27}=4.25\right.$, $P=0.025$, respectively), but no effect of sessions $\times$ drug treatment interaction $\left(\mathrm{F}_{6,81}=0.552, P=0.77\right)$. Post hoc comparisons for the total freezing showed that animals treated with both doses of JZL184 displayed significantly less freezing than control rats (Ps $<0.05$ ) (Figure $2 \mathrm{c}$ ). In the SI, ANOVA for SI time showed a significant effect of drug treatment $\left(\mathrm{F}_{2,27}=4.27, P=0.024\right)$ (Figure $\left.2 \mathrm{~d}\right)$. Rats treated with the higher dose of JZL184 $(1 \mathrm{mg} / \mathrm{kg})$ presented a tendency toward a decrease in the SI time as compared with vehicle-treated rats. However, post hoc comparisons did not reveal any statistical significant difference between animals treated with both doses of JZL184 $(0.5$ and $1 \mathrm{mg} / \mathrm{kg})$ and rats treated with vehicle. Finally, for WIN55,212-2, ANOVA for freezing showed a significant effect of sessions $\left(\mathrm{F}_{3,81}=28.40\right.$, $P<0.001)$ but no significant effects of drug treatment and sessions $\times$ drug treatment interaction $\left(\mathrm{F}_{2,27}=0.76, P=0.48\right.$; $\mathrm{F}_{6,81}=1.44, P=0.21$, respectively) (Figure $2 \mathrm{e}$ ). In the SI, ANOVA did not show any significant effect $\left(\mathrm{F}_{2,27}=0.32\right.$, $P=0.73$ ) (Figure 2f).

\section{Effects of Post-Extinction Cannabinoid Drug Administration on Trauma-Induced Behavioral Alterations}

In these experiments, we investigated the effects of the tested drugs, given immediately after the extinction sessions, on both cognitive and emotional modifications induced by trauma exposure.

Concerning URB597, ANOVA for freezing time showed a significant effect of sessions, drug treatment, and sessions $\times$ drug treatment interaction $\left(\mathrm{F}_{3,81}=38.14, \quad P<0.001\right.$; $\mathrm{F}_{2,27}=4.32, P=0.024 ; \mathrm{F}_{6,81}=2.22, P=0.050$, respectively). Post hoc comparisons showed that animals treated with the higher dose of URB597 $(0.3 \mathrm{mg} / \mathrm{kg})$ displayed significantly less freezing on the second $(P<0.05)$ and third $(P<0.05)$ extinction sessions when compared with vehicle-treated rats. In addition, animals treated with the $0.1 \mathrm{mg} / \mathrm{kg}$ dose displayed significantly less freezing on the third extinction session and the extinction retention session $\left(P_{\mathrm{S}}<0.05\right)$ when

Table I AEA and 2-AG Levels in Rats Subjected to the Extinction Sessions (Ext), in Rats Never Exposed to the Extinction Sessions (No-Ext) and in a Home-Cage Control Group (CTRL), in the Hippocampus (HIPP), Prefrontal Cortex (PFC), and Amygdala (AMY)

AEA (pmol/g tissue)

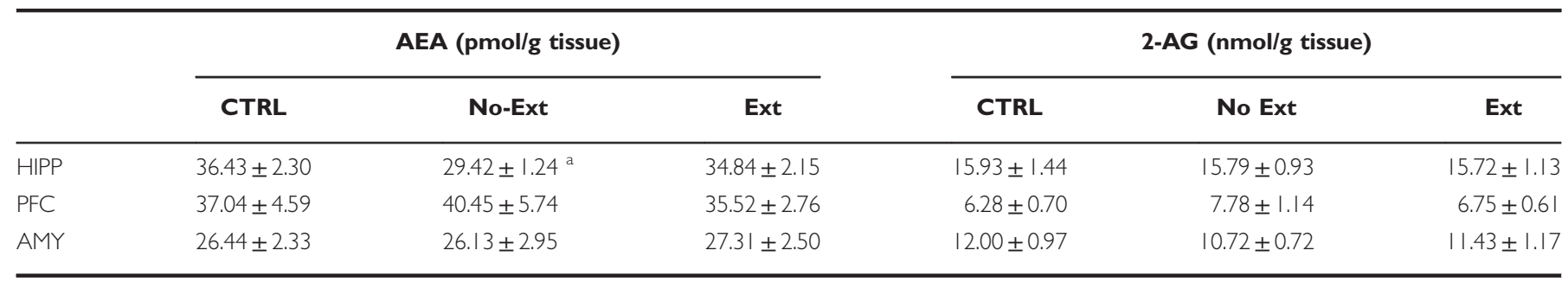

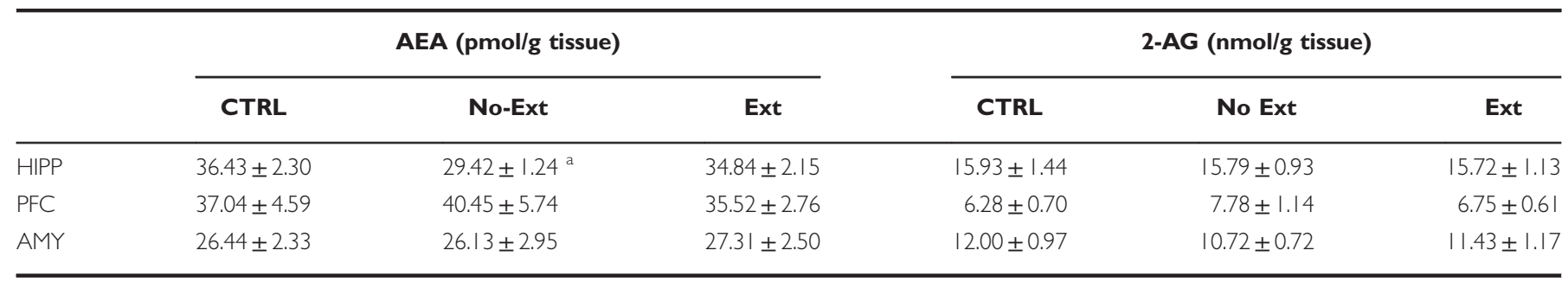

${ }^{a} P<0.05$ vs the corresponding CTRL group. Data are expressed as mean \pm SEM ( $n=8-10$ per group). 
compared with vehicle-treated rats. Post hoc tests for freezing time showed reduced total freezing in URB597-treated animals with respect to controls $(P<0.05)$ (Figure $3 \mathrm{a})$. In the SI, ANOVA showed a significant effect of drug treatment $\left(\mathrm{F}_{2,27}=5.80, \quad P=0.008\right)$. Post hoc analysis revealed that URB597- $(0.1 \mathrm{mg} / \mathrm{kg})$ treated rats interacted significantly more with the social partner than controls $(P<0.01)$ (Figure 3b). Concerning JZL184, ANOVA for freezing showed a significant effect of sessions $\left(\mathrm{F}_{3,81}=44.70\right.$, $P<0.001)$ and no significant effects of drug treatment and sessions $\times$ drug treatment interaction $\left(\mathrm{F}_{2,27}=0.79, P=0.47\right.$; $\mathrm{F}_{6,81}=1.75, P=0.12$, respectively) (Figure $3 \mathrm{c}$ ). In the SI, oneway ANOVA showed no significant drug treatment effect $\left(\mathrm{F}_{2,27}=0.092, P=0.91\right)$ (Figure 3d). Finally, ANOVA for WIN55,212-2 effects showed a significant effect of sessions and of sessions $\times$ drug treatment interaction $\left(\mathrm{F}_{3,99}=28.48\right.$, $P<0.001 ; \mathrm{F}_{6,99}=2.91, P=0.012$, respectively) but no drug treatment effect $\left(\mathrm{F}_{2,33}=1.29, P=0.29\right)$. Post hoc tests revealed that animals treated with the higher dose of WIN55,212-2 $(3 \mathrm{mg} / \mathrm{kg})$ displayed significantly less freezing during the fourth session (extinction retention session) when compared with vehicle-treated animals $(P<0.05)$ (Figure $3 \mathrm{e}$ ). In the SI, ANOVA did not show any significant drug treatment effect $\left(\mathrm{F}_{2,33}=0.86, P=0.43\right)$ (Figure $3 \mathrm{f}$ ).

\section{The Ameliorating Effects Of Post-Extinction URB597 Treatment are Specific for Trauma-Exposed Animals and Depend on Facilitation of Memory Extinction}

In this experiment, the effective dose of URB597 $(0.1 \mathrm{mg} / \mathrm{kg})$ was administered in rats never subjected to the footshock session, but only exposed to the experimental apparatus. Memory retention and SI were tested on days 16 and 17, respectively. We found that vehicle-treated rats exposed to the shock experience presented higher levels of freezing and reduction in SI as compared with their non-shocked controls. Moreover, URB597 did not affect freezing or social behavior in rats not exposed to the shock experience, yet it facilitated fear memory extinction and ameliorated emotional trauma-induced alterations present in the shockexposed animals. ANOVA for freezing did not reveal a significant effect of drug treatment $\left(\mathrm{F}_{1,28}=3.08, P=0.090\right)$, but did show a significant effect of the shock exposure, sessions, and drug treatment $\times$ shock exposure $\times$ sessions interaction $\quad\left(\mathrm{F}_{1,28}=154.20, \quad P<0.0001 ; \quad \mathrm{F}_{3,28}=17.30\right.$, $P<0.0001 ; \mathrm{F}_{3,84}=5.09, P<0.028$, respectively; Figure $\left.4 \mathrm{a}\right)$. Post hoc tests showed that vehicle-treated rats exposed to the shock experience presented higher levels of freezing across the extinction sessions as compared with the non-shock vehicle group $(P<0.05$, for all comparisons). Furthermore, shock-exposed rats given URB597 presented less freezing on the third extinction session and on the extinction retention session when compared with shock-exposed rats treated with vehicle $(\mathrm{Ps}<0.05)$. No significant differences were detected among shock-exposed rats treated with URB597 and rats not exposed to the trauma given vehicle or URB597, during the extinction retention session. Thus, URB597 treatment in shock-exposed animals completely restores animals' behavior, rendering it comparable to that observed in rats never exposed to the traumatic experience. Similarly, there were no significant differences across sessions between the two nonshocked animal groups (Figure $4 \mathrm{a}$ ). When analyzing the total freezing independently from the sessions, post hoc tests showed that, within vehicle-treated groups, shock-exposed animals showed significantly more freezing than no-shocked rats $(P<0.01)$. Similarly, within URB597-treated groups, shock-exposed animals showed significantly more freezing than URB597 no-shocked rats $(P<0.01)$. Moreover, among the shock-exposed groups, URB597-treated rats displayed significantly less freezing than the vehicle-treated group $(P<0.01)$. ANOVA for SI did not reveal a significant drug treatment $\left(\mathrm{F}_{1,28}=0.491, P=0.4893\right)$ or shock exposure $\left(\mathrm{F}_{1,28}=3.143, P=0.0872\right)$ effect, but showed a significant drug treatment $\times$ shock exposure interaction effect $\left(\mathrm{F}_{1,28}=5.427, P=0.0273\right)$. Post hoc comparisons showed that vehicle treated rats exposed to the shock experience presented reduced SI time $(P<0.05)$. URB597-treated rats exposed to the shock displayed higher levels of SI than vehicle-treated rats exposed to the same shock condition $(P<0.05)$, and comparable to those of non-shocked rats given either vehicle or URB597 (Figure 4b).

We next examined the effects of URB597 $(0.1,0.3 \mathrm{mg} / \mathrm{kg})$ administered in animals exposed to the trauma but not subjected to the repeated extinction procedure and exposed to the conditioned context only on day 16 (retention test). Rats were injected with URB597 on post-shock exposure day 7, 10, and 13. Results showed that neither freezing nor social behavior were affected by URB597 treatment when extinction sessions were omitted $\left(F_{2,26}=0.228, P=0.797\right)$ (Figure 4c). ANOVA did not reveal any significant effect of the drug treatment on SI time in the SI $\left(\mathrm{F}_{2,26}=0.593\right.$, $P=0.560)$ (Figure 4d).

\section{The Ameliorating Effects of Post-extinction URB597 Administration are Long-lasting and Blocked by Pre- treatment with the CB1 Receptor Antagonist SR141716}

In this experiment, we investigated whether post-extinction URB597 effects on both freezing and social behavior were dependent on indirect activation of $\mathrm{CB} 1$ receptors by increased AEA. We found that SR141716, at a dose (1 mg/ $\mathrm{kg}$ ) not altering the behavior per se, blocked the ameliorating effects of URB597 $(0.1 \mathrm{mg} / \mathrm{kg})$ on both freezing and social behavior, at day 16 and 17 post-trauma exposure. ANOVA for freezing revealed a significant effect of the sessions, of the drug treatment and of sessions $\times$ drug treatment interaction $\left(\mathrm{F}_{3,108}=57.16, P<0.001 ; \mathrm{F}_{3,36}=3.82, P=0.018 ; \mathrm{F}_{3,108}=2.23\right.$, $P=0.026$, respectively). Post hoc tests showed that URB597treated rats displayed less freezing on the second and third extinction sessions and on the extinction retention session when compared with rats receiving SR141716 alone $(P$ s $<0.05)$. Moreover, URB597-treated rats displayed less freezing than SR141716/URB597-treated rats on the third extinction session and on the extinction retention session $(P s<0.05)$. Finally, URB597-treated rats displayed less freezing than vehicle-treated rats on the extinction retention session $(P<0.01)$. When analyzing total freezing independently from the sessions, post hoc tests showed that URB597treated animals displayed significantly less freezing than the vehicle-treated group $(P<0.05)$. No differences were observed among the groups of rats treated with SR141716/ URB597, SR141716, or vehicle alone (Figure 5a). ANOVA for SI time also revealed a significant effect of the drug treatment $\left(\mathrm{F}_{3,36}=4.549, P=0.008\right)$. Post hoc analysis showed that rats 


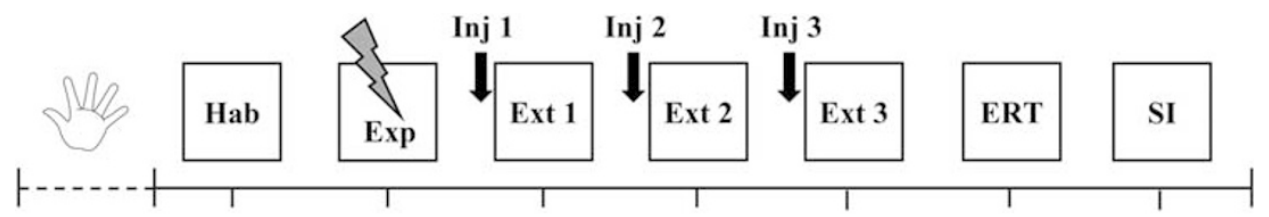

$$
7 \text { days day }-1 \text { day } 0 \text { day } 7 \text { day } 10 \text { day } 13 \text { day } 16 \text { day } 17
$$

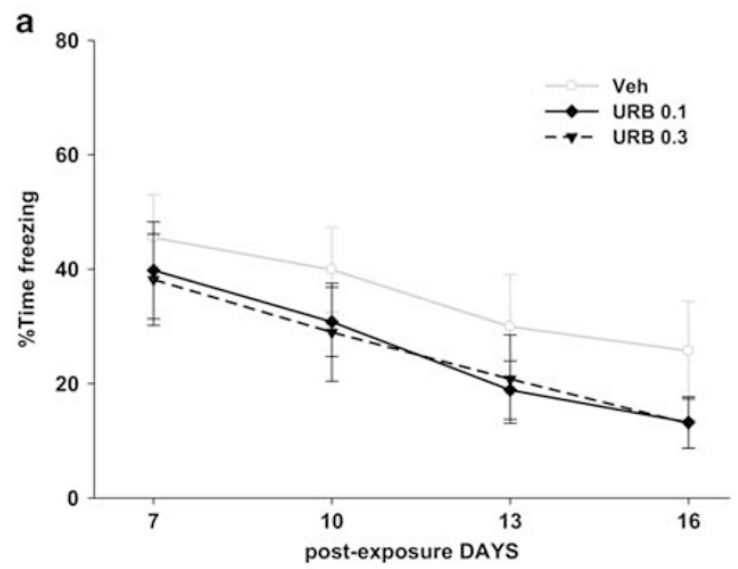

b
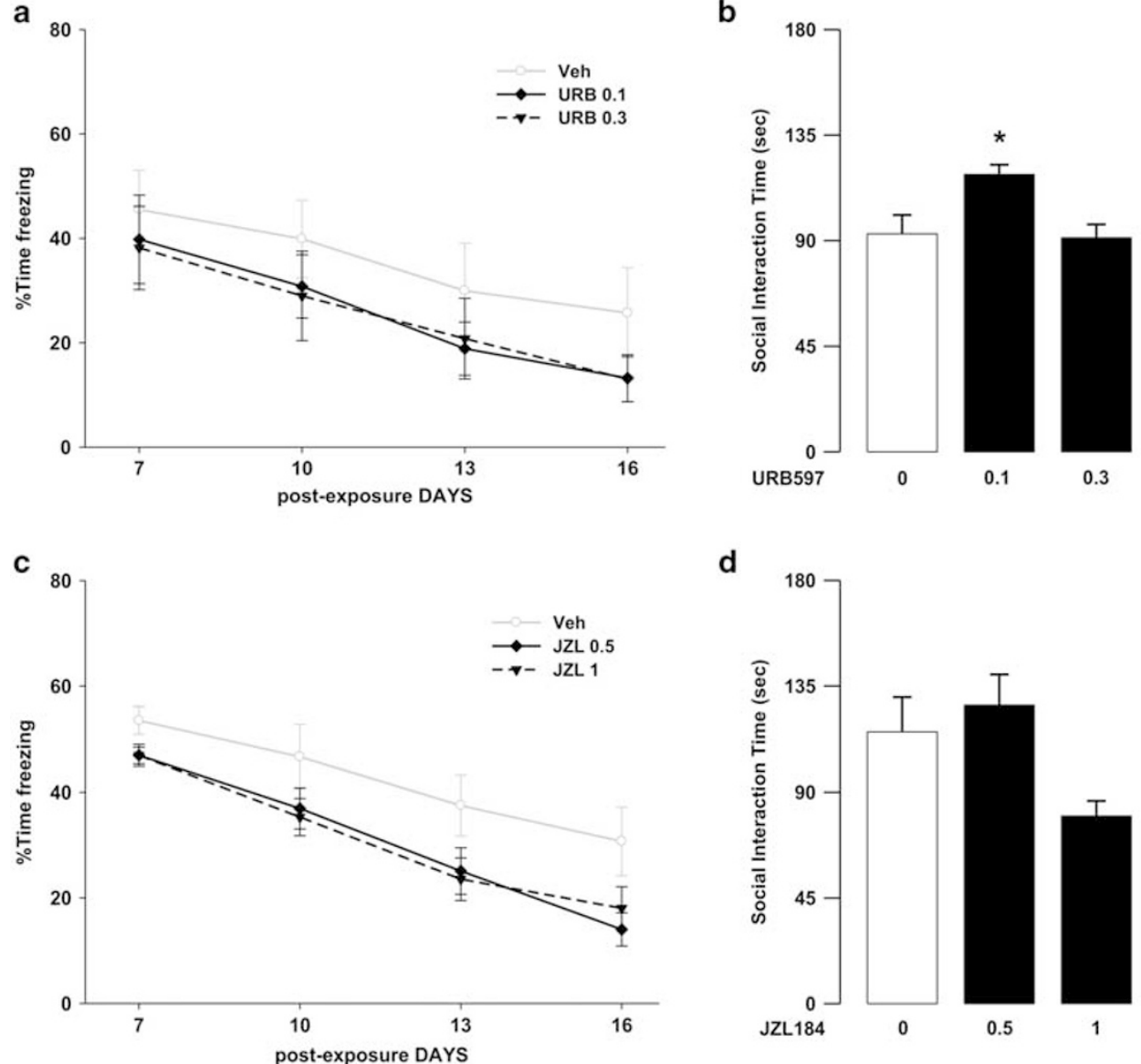

d
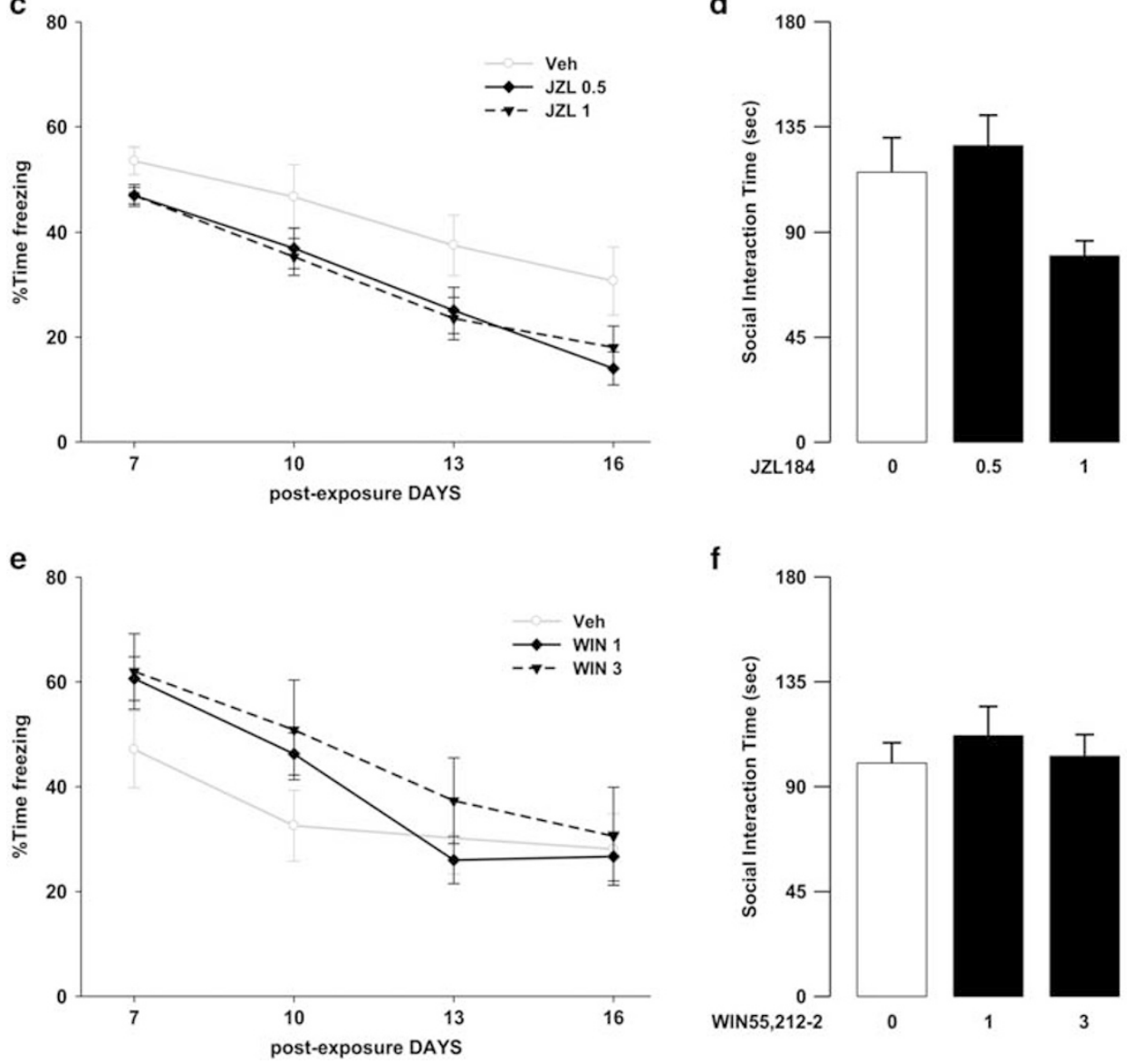

Figure 2 Freezing rates across (a) the three extinction sessions (Ext I, 2, and 3) and the extinction retention test (ERT) and (b) social interaction (SI) time of rats treated with URB597 or vehicle (Veh) I h before the extinction sessions on day 7, I0, and I3. Freezing rates across (c) the three extinction sessions and the extinction retention test and (d) social interaction time of rats treated with JZLI84 or vehicle I h before the extinction sessions on day 7 , I0, and I3. Freezing rates across (e) the three extinction sessions and the extinction retention test and ( $\mathrm{f}$ ) social interaction time of rats treated with WIN55,2I2-2 or vehicle I h before the extinction sessions on day 7, I0, and I3. $* P<0.05$ URB597 0.I mg/kg vs Veh. Data are expressed as mean \pm SEM ( $n=8-11$ per group). 

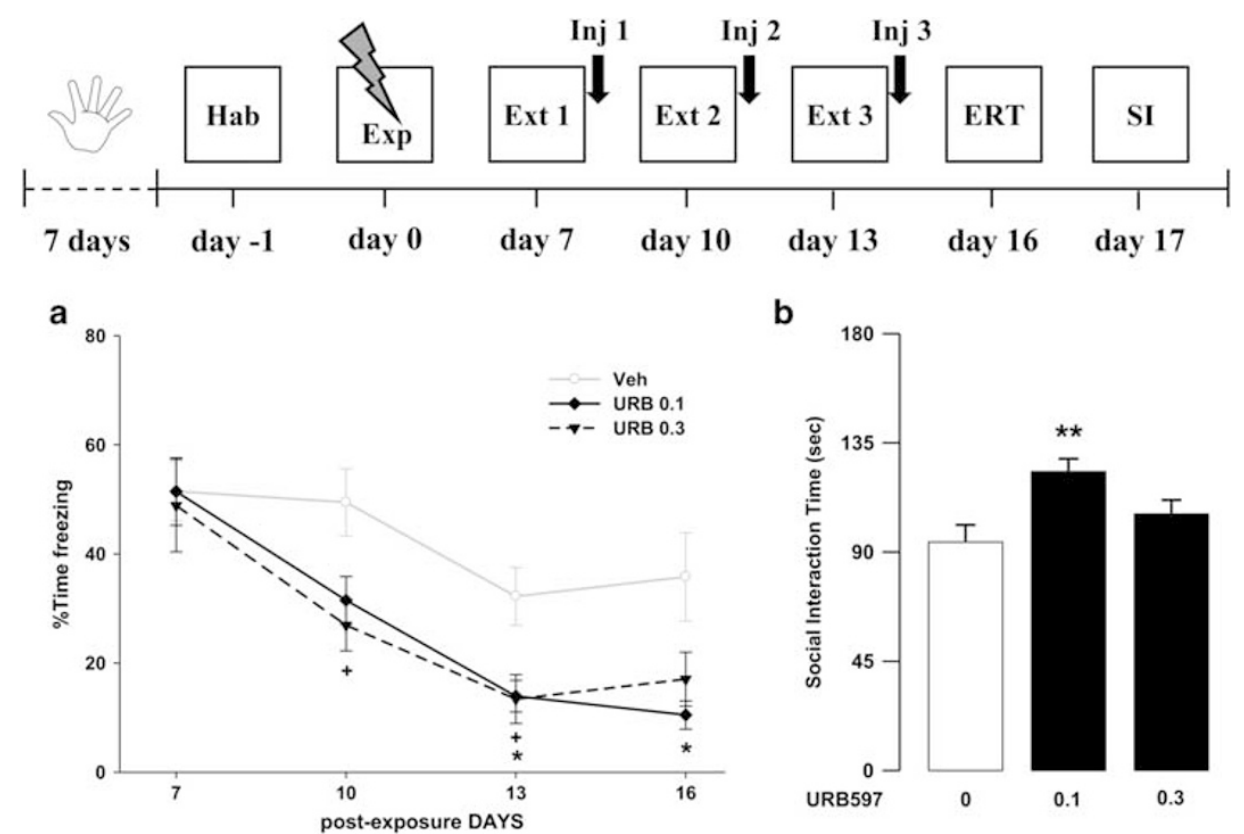

b
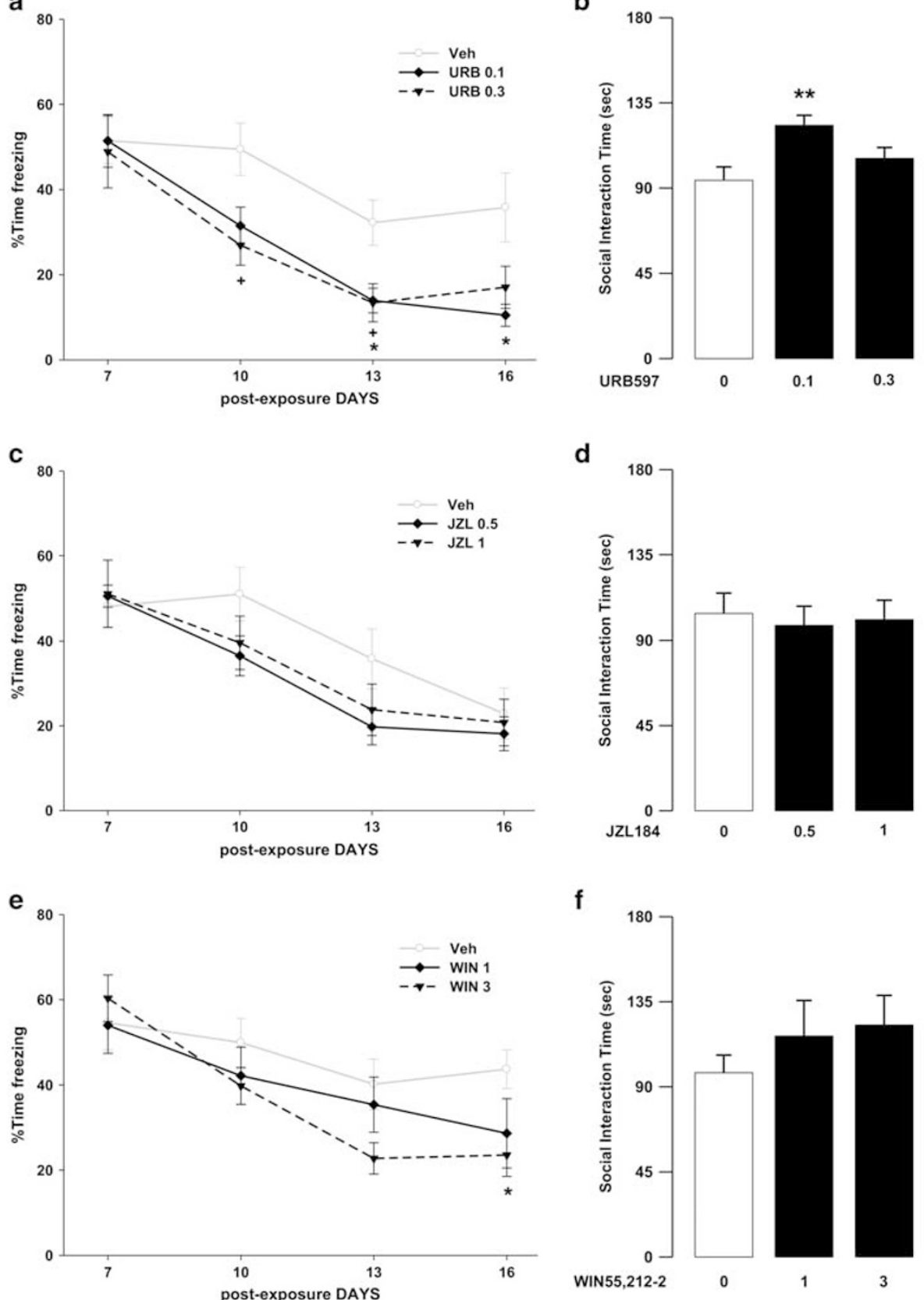

d

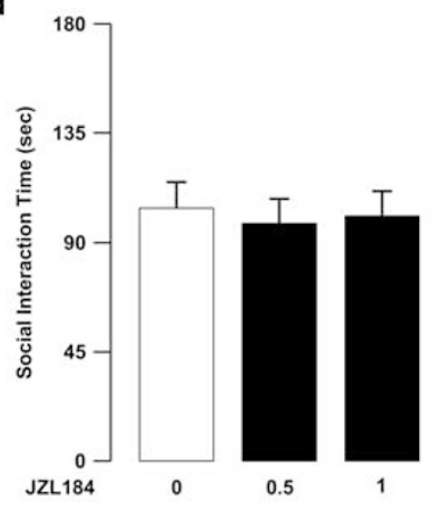

f

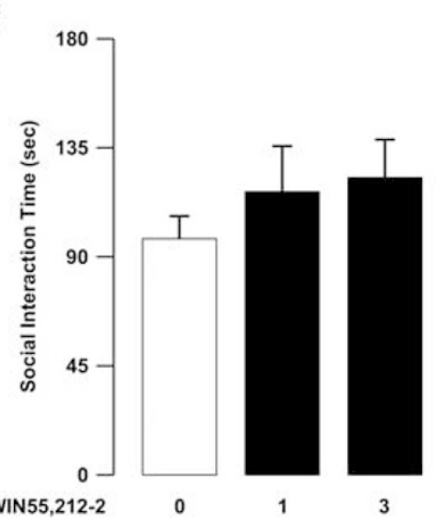

Figure 3 Freezing rates across (a) the three extinction sessions (Ext I, 2, and 3) and the extinction retention test (ERT) and (b) social interaction (SI) time of rats treated with URB597 or vehicle (Veh) immediately after the extinction sessions on day 7, I0, and I3 (*P<0.05, **P $<0.01$, URB597 $0.1 \mathrm{mg} / \mathrm{kg}$ vs Veh; ${ }^{+} P<0.05$, URB597 $0.3 \mathrm{mg} / \mathrm{kg}$ vs Veh). Freezing rates across (c) the three extinction sessions and the extinction retention test and (d) social interaction time of rats treated with JZLI84 or vehicle immediately after the extinction sessions on day 7, 10, and I3. Freezing rates across (e) the three extinction sessions and the extinction retention test, and $(f)$ social interaction time of rats treated with WIN55,2 I 2-2 or vehicle immediately after the extinction sessions on day 7,10 , and 13 (*P<0.05, WIN55,212-2 $3 \mathrm{mg} / \mathrm{kg}$ vs Veh). Data are expressed as mean+SEM ( $n=10-13$ per group). 

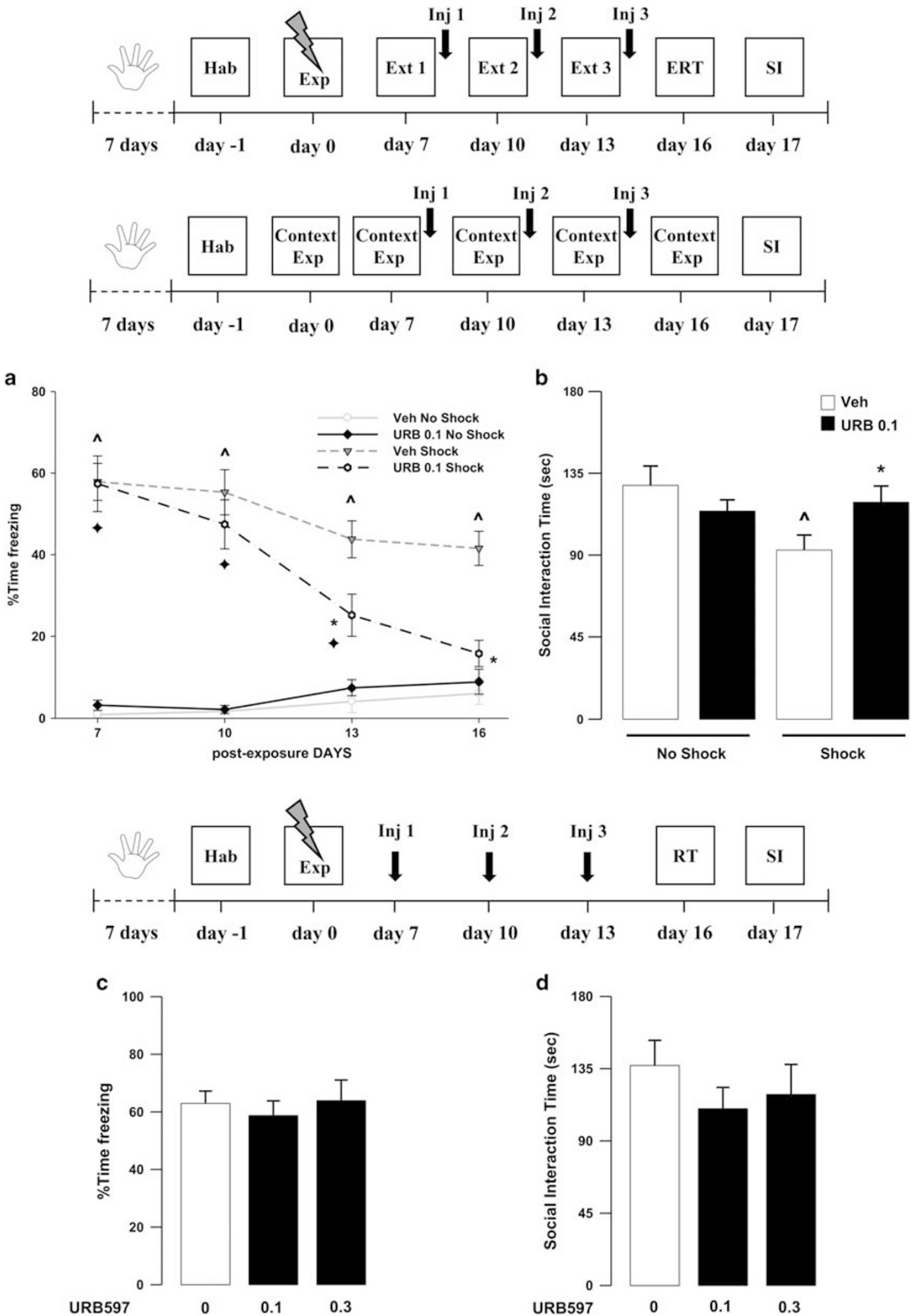

Figure 4 Freezing rates across (a) the three extinction sessions (Ext I, 2, and 3) and extinction retention test (ERT) and (b) social interaction (SI) time of rats treated with URB597 (0.1 mg/kg; URB 0.I Shock) or vehicle (Veh Shock) immediately after the extinction sessions on day 7, I0, and I3, exposed to the traumatic experience (Exp) or never presented the shock but only exposed to the experimental context (Context Exp; URB 0.I No Shock, Veh No Shock). (c) Freezing rates of rats exposed to the shock experience (Exp), but not to the extinction sessions and treated with URB597 or vehicle on day 7 , I0, and I3, as assessed during the retention session (RT) on day 16. (d) Social interaction time of the same rats during the SI test on day I7. ^P<0.05, Veh Shock vs Veh No Shock; $* P<0.05$, URB 0.1 Shock vs Veh Shock; $P<0.05$, URB 0.I Shock vs URB 0.I No Shock. Data are expressed as mean \pm SEM $(n=7-I$ I per group). 

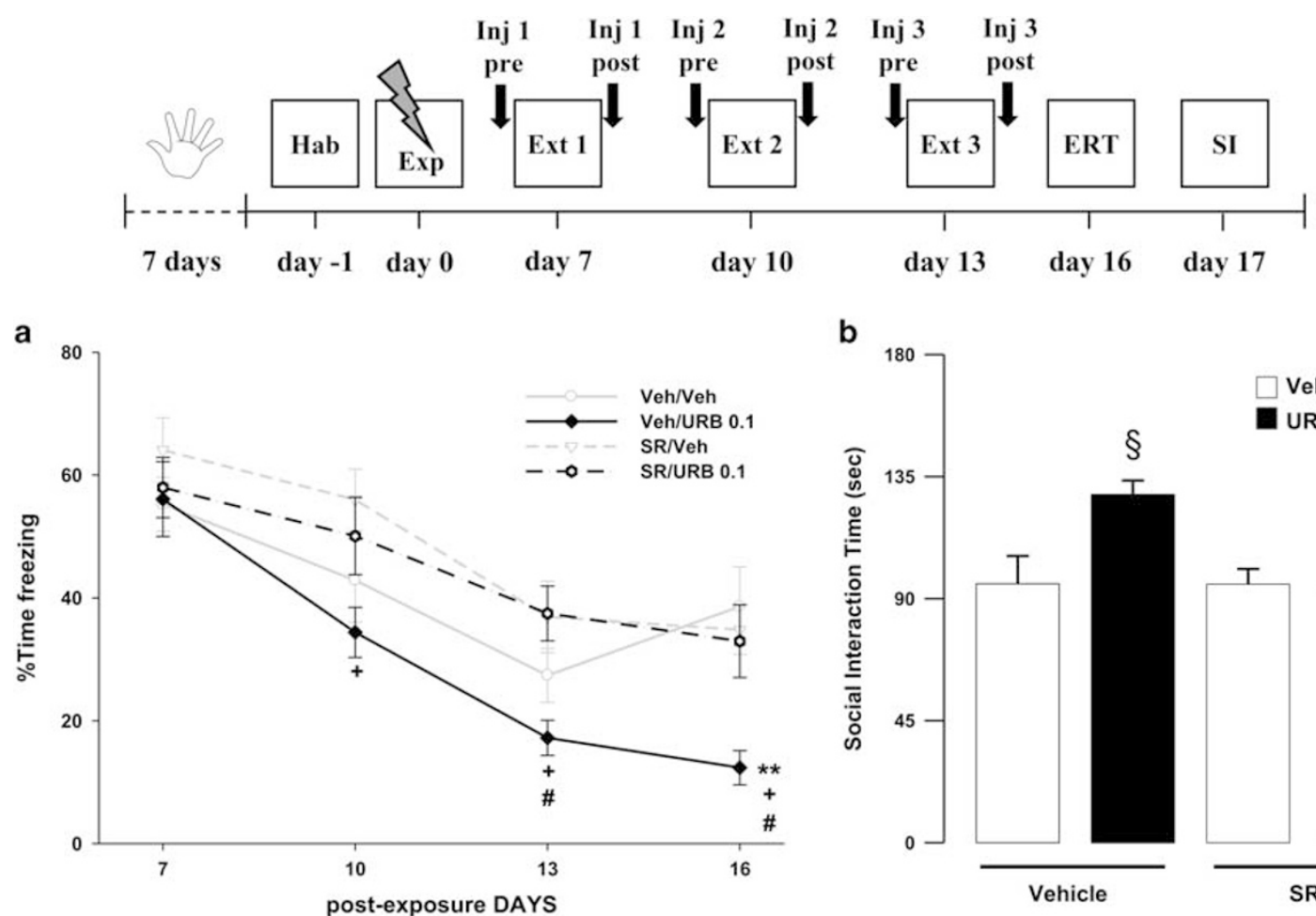

b
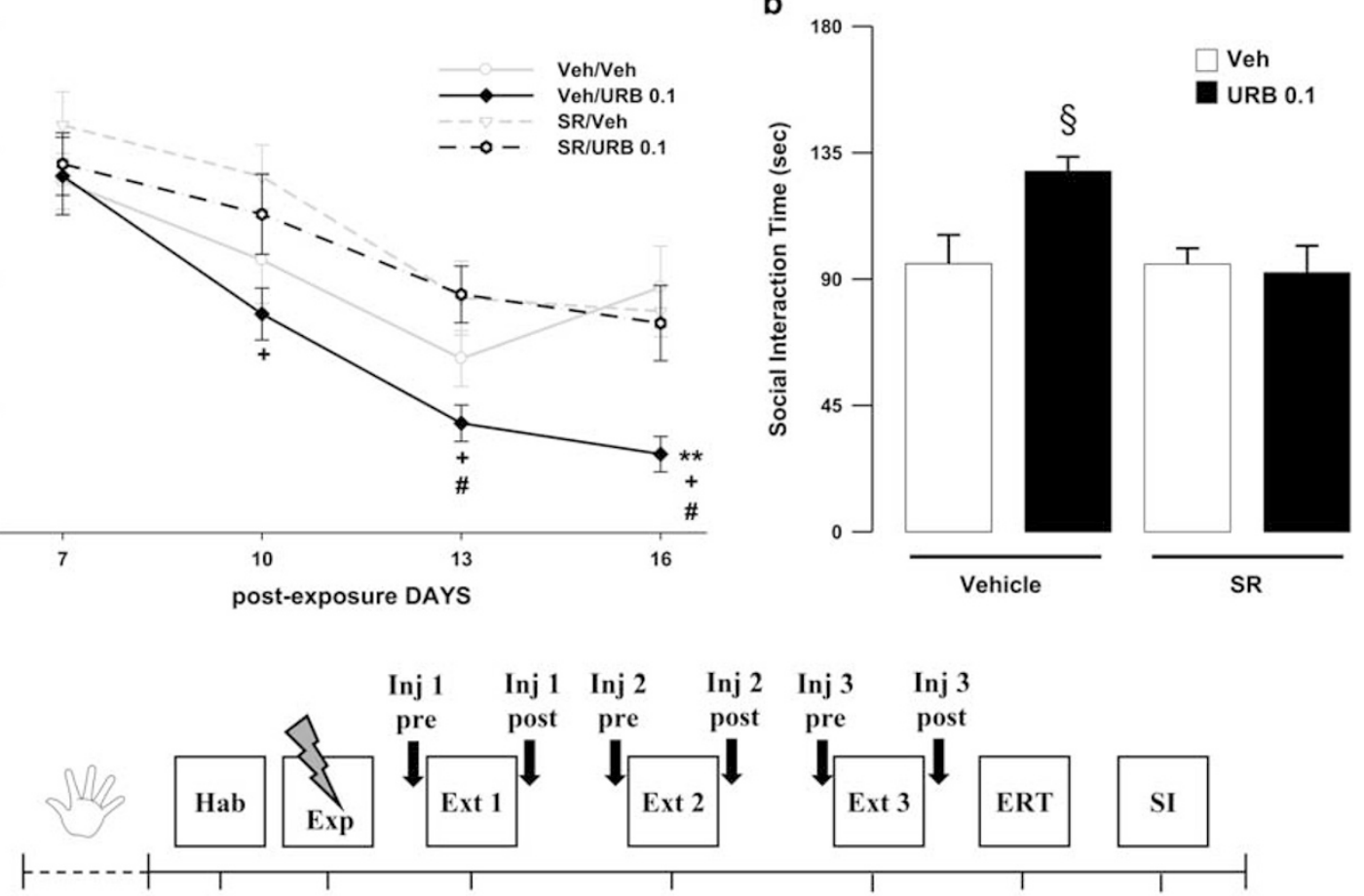

7 days day -1 day 0 day 7 day $10 \quad$ day 13 day 36 day 37
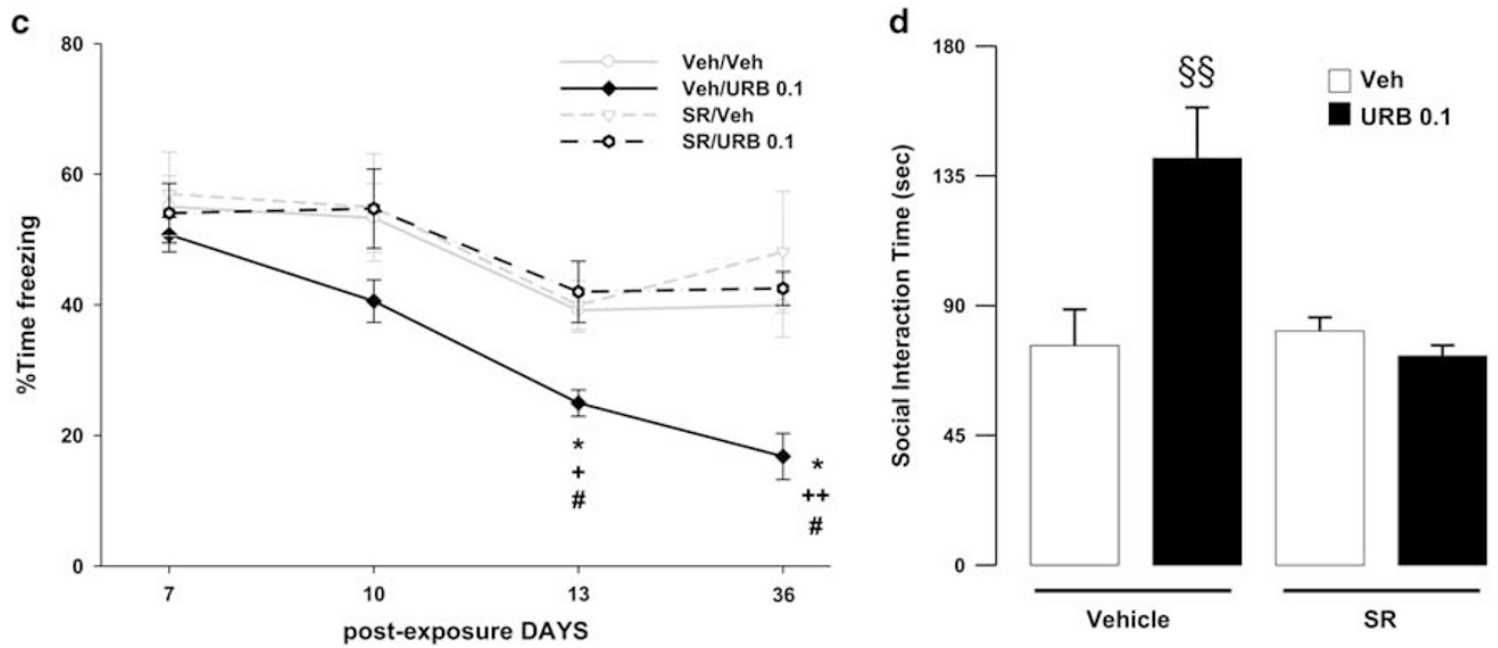

Figure 5 Freezing rates across (a) the three extinction sessions (Ext I, 2, and 3) and extinction retention test (ERT, day I6) and (b) social interaction (SI) time (day 17) of rats treated with SR I4I7I6 (SR, I mg/ $/ \mathrm{kg}$ ) or vehicle (Veh) 30 min before, and with URB597 (0.I mg/kg, URB 0.I) or vehicle immediately after the extinction sessions on day 7, 10, and 13. Freezing rates across (c) the three extinction sessions and extinction retention test (day 36) and (d) social interaction time (day 37) of rats treated with SRI4I7I6 (I mg/kg) or vehicle 30 min before, and with URB597 $(0.1 \mathrm{mg} / \mathrm{kg})$ or vehicle immediately after the extinction sessions on day 7, I0, and 13. $* P<0.05$, $* * *<<0.01$, Veh/URB 0.1 vs Veh/Veh; ${ }^{+} P<0.05,{ }^{++} P<0.0$ I, Veh/URB 0.1 vs SRVeh; ${ }^{\#} P<0.05$, Veh/URB 0.1 vs SR/URB 0.I; ${ }^{\S} P<0.05,{ }^{\S} P<0.01$, Veh/URB 0.1 vs each other group). Data are expressed as mean+SEM ( $n=8-10$ per group). 
treated with URB597 interacted longer with the social partner than rats from the other groups did $\left(P_{s}<0.05\right)$. No significant differences were observed among SR141716/ URB597, SR141716, or vehicle-treated groups (Figure 5b).

We next examined whether post-extinction URB597 effects on both freezing and social behavior were longlasting. Animals underwent the same drug administration regimen and 3-day extinction session exposure, as described for the previous experiment, except that the extinction retention test and social behavior were examined more than a month after trauma exposure (day 36 and 37, for freezing and social interaction, respectively). We found that control rats still presented robust trauma-related behavioral alterations at day 36 and 37 post-trauma exposure. However, URB597 treatment $(0.1 \mathrm{mg} / \mathrm{kg})$ combined with the extinction exposure sessions reduced freezing and restored normal SI, which remained stable long after treatment termination. In addition, these effects were blocked by pre-administration of SR141617 (1 mg/kg), thus showing that URB597 effects are dependent on indirect activation of $\mathrm{CB} 1$ receptors through increased levels of AEA.

ANOVA for freezing revealed a significant effect of the sessions, of the drug treatment and of sessions $\times$ drug treatment interaction $\left(\mathrm{F}_{3,28}=30.02, P<0.0001 ; \mathrm{F}_{3,28}=3.39\right.$, $P=0.032 ; \mathrm{F}_{3,84}=2.050, P=0.044$, respectively). Post hoc tests showed that URB597-treated rats displayed less freezing on the third extinction session and on the extinction retention session when compared with rats receiving vehicle alone or SR141716/URB597 (Ps<0.05). Moreover, URB597-treated rats displayed less freezing than rats treated with SR141716 alone on the third extinction session $(P<0.05)$ and on the extinction retention session $(P<0.01)$. When analyzing the total freezing independently from the sessions, post hoc tests showed that URB597-treated animals displayed significantly less freezing than the controls $(P<0.01)$. No differences were observed among the other groups of rats (Figure $5 \mathrm{c}$ ). ANOVA for SI time also revealed a significant effect of the drug treatment $\left(\mathrm{F}_{3,28}=8.370, P=0.0004\right)$. Post hoc analysis showed that rats treated with URB597 interacted longer with the social partner than rats from the other groups did $(P s<0.01)$. No significant differences were observed among the other groups (Figure 5d).

\section{DISCUSSION}

The present findings show that facilitation of endocannabinoid signaling augments the efficacy of extinction training and ameliorates the behavioral alterations caused by traumatic stress in rats. We previously showed that exposure to footshocks in rats, together with social isolation, induced a long-lasting reduction in social behavior paired with excessive retrieval for the traumatic experience, leading to chronic dysfunction (Berardi et al, 2014). In particular, we showed that exposure to footshocks induces a long-lasting form of contextual fear memory characterized by extremely high freezing rates, still present even 3 months after stress exposure. This highlights the chronic nature of the fear memory, a main feature of the human PTSD pathology. It is of interest, also from a translational point of view, that the stressful experience caused a chronic alteration of social behavior as well (Berardi et al, 2014).
Here, we aimed at mimicking a classical setting of exposure therapy in humans by establishing, in rats, a form of spaced extinction learning induced by repeated exposures to the context in the absence of footshocks and paralleled by drug administrations (Abramowitz, 2013; de Quervain et al, 2011). We observed a reduction in freezing behavior 2 weeks after exposure to trauma in animals that were repeatedly exposed to a no longer dangerous context when compared with rats that were not subjected to the extinction sessions, thus highlighting that the exposure sessions can dampen per se fear memory recall. Furthermore, compared with home cage control animals, rats never exposed to the repeated extinction procedure presented decreased hippocampal AEA levels when measured immediately after the SI session, at the end of our behavioral paradigm. Interestingly, in the same brain region, AEA levels in animals subjected to the spaced extinction sessions were comparable to those observed in home cage control animals. Since we did not observe any change in the Extinction group, subjected to the same SI testing before measuring endocannabinoid levels, it is unlikely that the reduction of AEA levels in the NoExtinction group might be ascribed to acute phasic changes owing to the prior SI testing. Our finding rather suggests that the traumatic experience in the absence of the repeated extinction procedure might have caused a tonic reduction of AEA levels in the hippocampus. Consistently with human data on extinction therapy in PTSD patients (Bisson et al, 2013; Quirk et al, 2010), the present finding suggests that repeated exposure to trauma-related reminders, in the absence of negative consequences, represents a useful approach to dampen the excessive recall of the traumatic memory. However, the repeated exposure to trauma-related reminders alone is not sufficient to normalize stress-induced aberrations in social behavior (Berardi et al, 2014). Therefore, we tested whether administrations of drugs enhancing endocannabinoid signaling before or after the three extinction sessions, could be effective in restoring a normal behavioral phenotype. Drugs were administered either 1 hour before, or immediately after, each extinction session, in order to disentangle the impact of drug treatment on the retrieval or the consolidation of extinction, respectively. To reduce the development of drug tolerance, rats were exposed to the extinction sessions on spaced days. Of note, this procedure was reported to be more effective than extinction sessions carried out on consecutive days (Matsuda et al, 2014). When drug injections were given $1 \mathrm{~h}$ before the extinction sessions, none of the tested compounds were able to improve extinction learning and social behavior at the same time. Noteworthy, boosting AEA signaling with URB597 administration, promoted social behavior while leaving the recall of the traumatic event unaltered. Conversely, JZL184 administration, slightly reduced the traumatic memory recall but failed to improve social behavior.

Different results were observed with post-extinction treatment. Although JZL184 did not produce any significant effect, the CB receptor agonist WIN55,212-2 facilitated memory extinction while leaving the social behavior unaltered. Interestingly, URB597, through indirect activation of $\mathrm{CB} 1$ receptors, enhanced the consolidation of extinction, as well as ameliorated the trauma-induced alterations in social behavior by increasing the levels of social interaction. We also found that these ameliorating effects of URB597 
were dependent on the traumatic experience. By replicating our previous findings (Berardi et al, 2014), our results showed that vehicle-treated rats presented impairments in social behavior and, clearly, higher levels of freezing, 2 weeks after trauma exposure as compared with rats that never experienced the traumatic event. Treatment with URB597 did not affect freezing or social behavior in non-shocked rats, thus showing that the ameliorating effects of URB597 were specific for rats exposed to the footshock experience. Most importantly, URB597 treatment in traumatized animals completely restored fear extinction and SI behavior, rendering it comparable to that observed in rats never exposed to the traumatic experience.

In addition to this, in a separate experiment we found that the efficacy of URB597 treatment was also strictly dependent on the repeated exposure-based extinction approach. Indeed, when animals were treated at the same time intervals of those of the extinction procedure, but without re-exposing them to the context, URB597 did not produce any effect on freezing rates or social behavior. This clearly demonstrates that the beneficial effects of URB597 cannot be attributed solely to the drug, but instead appear to augment the efficacy of the extinction training.

Furthermore, we evaluated the long-term efficacy of URB597 treatment combined with the repeated extinction session procedure. When vehicle-treated rats were tested for extinction retention and social behavior $>1$ month after shock-exposure, they still presented significant behavioral dysfunctions. Of note, treatment with URB597 considerably decreased freezing behavior and increased the time spent in social interaction, more than a month after trauma exposure and 3 weeks after the last drug injection. Moreover, we also found that these effects were blocked by pre-treatment with the CB1 receptor antagonist SR141716, thus showing that URB597 effects are dependent on indirect activation of CB1 receptors through increased levels of AEA.

These behavioral results are consistent with our biochemical data indicating that reductions in AEA content in the hippocampus produced by traumatic stress, were absent in the animals exposed to extinction training. Consistent with previous reports (Gunduz-Cinar et al, 2013; Marsicano et al, 2002), this suggests that extinction training increases endogenous AEA signaling and that augmentation of this effect, through inhibition of AEA hydrolysis, enhances the efficacy of extinction training. Taken together, these results demonstrate that URB597, by increasing AEA levels, can promote extinction consolidation, reducing the emotional consequences of traumatic stress as well, through increasing AEA signaling capacity at CB1 receptors.

The fact that traumatic stress produced a sustained reduction in hippocampal AEA content is consistent with previous reports that stress or glucocorticoids can cause delayed and lasting reductions in hippocampal AEA content (Bowles et al, 2012; Hill et al, 2008a, 2008b; Wang et al, 2012). It is interesting to speculate that the reduction of AEA hippocampal levels might be responsible of the long-lasting effects on memory and social behavior observed in rats exposed to the trauma. However, given that extinction procedure alone restored normal levels of hippocampal AEA and was sufficient to reduce the cognitive effects of trauma, but at the same time insufficient to significantly increase social behavior, this suggests that the restoration of AEA signaling may be more specific to the cognitive effects as opposed to social behavior. That being said, amplification of AEA signaling during the extinction training session did normalize alterations in social behavior indicating that these changes in AEA signaling may indeed be relevant for alterations in social behavior. These data are particularly interesting in light of recent findings indicating that AEA signaling in the hippocampus is critical for safety learning (Micale et al, 2017), suggesting that augmentation of hippocampal AEA signaling may have broad spanning therapeutic mechanisms in the suppression of emotionally aversive memories.

Our results may be of help in understanding why the URB597-mediated AEA enhancement is more efficacious with respect to the JZL184-mediated 2-AG enhancement in the promotion of the consolidation of extinction of the traumatic memories. Even though AEA and 2-AG act on the same receptors, distinct behavioral effects are frequently reported in literature (Manduca et al, 2015; Morena et al, 2015). For example, exposure to stress generally results in a decrease in AEA and a parallel increase in 2-AG levels (Morena et al, 2016b). Here we did not observe any changes in the tissue content of $2-\mathrm{AG}$, at least at the discrete time points where we analyzed endocannabinoid levels, but the reduction of freezing induced by JZL184 administered $1 \mathrm{~h}$ before the extinction session, is in line with the retrievaldampening effects of JZL184 (Morena et al, 2015). The present results provide evidence as to why AEA elevation could represent a better therapeutic approach than synthetic direct cannabinoid agonists in PTSD treatment. Indeed, the synthetic cannabinoid agonist WIN55,212-2, by indistinctly activating cannabinoid receptors, did not produce any significant improvement in the behaviors of traumatized rats except for a reduction of freezing rates when given post extinction. Conversely URB597, by acting only on those brain areas where there is an active endocannabinoid transmission, can selectively promote AEA modulatory influences on memory and behavior. It is also important to note that URB597, differently from direct cannabinoid agonists, lacks the classical cannabinoids side-effects such as catalepsy, hypothermia, hyperphagia, as well as abuse potential (Piomelli et al, 2006).

In support to our findings, a large body of preclinical and clinical research reports the potential benefit of cannabinoids in the treatment of PTSD symptomatology, including hyperarousal, sleep disturbances, and heightened anxiety (Hill et al, 2017; Jetly et al, 2015; Morena et al, 2016a).

Studies on preclinical traumatic stress/PTSD models have suggested that cannabinoid treatment could prevent the development of PTSD-like symptomatology (increased startle response, impairments in hippocampus- and amygdala-dependent memory) when administered in proximity to trauma exposure (Korem and Akirav, 2014; Shoshan et al, 2017). Although these studies give important insights into the mechanisms involved in stress-related processes, from a translational point of view, however, it would be difficult to predict whether a person would develop PTSD after a traumatic event. However, a successful therapeutic approach would be represented by enhancement of extinction learning through exposure psychotherapy. Growing evidence reveals the importance of cognitive enhancers augmenting the efficacy of exposure therapy to treat trauma 
and anxiety-related disorders (Singewald et al, 2015). In this scenario, our results suggest that drugs elevating AEA signaling at CB1 receptors could be successfully coupled with the exposure therapy to increase its efficacy and reduce both the cognitive and emotional dysfunctions induced by exposure to traumatic stress, thus potentially restoring normal behavior, which we found to remain stable long after trauma-exposure and pharmacological treatment termination. The fact that URB597 drug intervention could be potentially coupled and limited only to the behavioral exposure psychotherapy, preserving its efficacy and, at the same time, avoiding a chronic administration regimen, would represent a considerable advantage both in terms of promoting drug compliance and minimizing potential side effects on other physiological and/or psychological functions. Taken together, our findings have a remarkable translational relevance to the potential importance of FAAH inhibition in the treatment of PTSD. Further studies are needed to confirm the present findings in additional animal models of traumatic stress, but also in clinical settings where the utility of FAAH inhibitors for the treatment of PTSD has become a potential novel therapeutic target.

\section{FUNDING AND DISCLOSURE}

The authors declare no conflict of interest. This study was supported by grants from the Human Frontier Science Program (RGY0077), Italian Ministry of Education MIUR (RBFR10XKHS; 2015SKN9YT_002) to P.C., Sapienza University 'Avvio alla ricerca 2014 and 2015' (C26N143X3Z, C26N152HTL, respectively) to A.B. M.M. is the recipient of Postdoctoral Fellowships from the Canadian Institutes of Health Research (CIHR) and Alberta Innovates Health Solutions (AIHS). This work was also supported by operating funds from CIHR to M.N.H. and M.N.H. receives salary support in the form of a Tier II Canada Research Chair from CIHR.

\section{ACKNOWLEDGMENTS}

We thank Daniela Valeri, Maria Grazia Coseglia, Sonia Frusciante and Nicoletta Marinelli for technical help, and the Southern Alberta Mass Spectrometry Centre, located in and supported by the Cumming School of Medicine, University of Calgary, for their services in targeted liquid chromatography tandem mass spectrometry.

\section{REFERENCES}

Abramowitz JS (2013). The practice of exposure therapy: relevance of cognitive-behavioral theory and extinction theory. Behav Ther 44: 548-558.

American Psychiatric Association. American Psychiatric Association; (2013). Diagnosticand Statistical Manual of Mental Disorders.

Atsak P, Hauer D, Campolongo P, Schelling G, McGaugh JL, Roozendaal B (2012). Glucocorticoids interact with the hippocampal endocannabinoid system in impairing retrieval of contextual fear memory. Proc Natl Acad Sci USA 109: 3504-3509.

Berardi A, Trezza V, Palmery M, Trabace L, Cuomo V, Campolongo P (2014). An updated animal model capturing both the cognitive and emotional features of post-traumatic stress disorder (PTSD). Front Behav Neurosci 8: 142.
Bisson JI, Roberts NP, Andrew M, Cooper R, Lewis C (2013). Psychological therapies for chronic post-traumatic stress disorder (PTSD) in adults. Cochrane database Syst Rev CD003388.

Bitencourt RM, Pamplona FA, Takahashi RN (2014). Corticosteroidendocannabinoid loop supports decrease of fear-conditioned response in rats. Eur Neuropsychopharmacol 24: 1091-1102.

Bowers ME, Ressler KJ (2015). Interaction between the cholecystokinin and endogenous cannabinoid systems in cued fear expression and extinction retention. Neuropsychopharmacology 40: $688-700$.

Bowles NP, Hill MN, Bhagat SM, Karatsoreos IN, Hillard CJ, McEwen BS (2012). Chronic, noninvasive glucocorticoid administration suppresses limbic endocannabinoid signaling in mice. Neuroscience 204: 83-89.

Campolongo P, Morena M, Scaccianoce S, Trezza V, Chiarotti F, Schelling G et al (2013). Novelty-induced emotional arousal modulates cannabinoid effects on recognition memory and adrenocortical activity. Neuropsychopharmacology 38: 1276-1286.

Chen X, Li Y, Li S, Kirouac GJ (2012). Early fear as a predictor of avoidance in a rat model of post-traumatic stress disorder. Behav Brain Res 226: 112-117.

Chhatwal JP, Davis M, Maguschak KA, Ressler KJ (2005). Enhancing cannabinoid neurotransmission augments the extinction of conditioned fear. Neuropsychopharmacology 30: 516-524.

Choi DC, Rothbaum BO, Gerardi M, Ressler KJ (2010). Pharmacological enhancement of behavioral therapy: focus on posttraumatic stress disorder. Curr Top Behav Neurosci 2: 279-299.

Cravatt BF, Giang DK, Mayfield SP, Boger DL, Lerner RA, Gilula NB (1996). Molecular characterization of an enzyme that degrades neuromodulatory fatty-acid amides. Nature 384: 83-87.

de Quervain DJ-F, Bentz D, Michael T, Bolt OC, Wiederhold BK, Margraf J et al (2011). Glucocorticoids enhance extinction-based psychotherapy. Proc Natl Acad Sci USA 108: 6621-6625.

Di Marzo V (1999). Biosynthesis and inactivation of endocannabinoids: relevance to their proposed role as neuromodulators. Life Sci 65: 645-655.

Dinh TP, Carpenter D, Leslie FM, Freund TF, Katona I, Sensi SL et al (2002). Brain monoglyceride lipase participating in endocannabinoid inactivation. Proc Natl Acad Sci USA 99: 10819-10824.

Furini C, Myskiw J, Izquierdo I (2014). The learning of fear extinction. Neurosci Biobehav Rev 47: 670-683.

Gunduz-Cinar O, MacPherson KP, Cinar R, Gamble-George J, Sugden K, Williams B et al (2013). Convergent translational evidence of a role for anandamide in amygdala-mediated fear extinction, threat processing and stress-reactivity. Mol Psychiatry 18: 813-823.

Gutner CA, Gallagher MW, Baker AS, Sloan DM, Resick PA (2016). Time course of treatment dropout in cognitive-behavioral therapies for posttraumatic stress disorder. Psychol Trauma 8: $115-121$.

Haller J, Barna I, Barsvari B, Gyimesi Pelczer K, Yasar S, Panlilio L V. et al (2009). Interactions between environmental aversiveness and the anxiolytic effects of enhanced cannabinoid signaling by FAAH inhibition in rats. Psychopharmacology (Berl) 204: 607-616.

Hauer D, Ratano P, Morena M, Scaccianoce S, Briegel I, Palmery M et al (2011). Propofol enhances memory formation via an interaction with the endocannabinoid system. Anesthesiology 114: 1380-1388.

Heim C, Nemeroff CB (2009). Neurobiology of posttraumatic stress disorder. CNS Spectr 14: 13-24.

Hill MN, Campolongo P, Yehuda R, Patel S (2017). Integrating endocannabinoid signaling and cannabinoids into the biology and treatment of posttraumatic stress disorder. Neuropsychopharmacology 43: 80-102.

Hill MN, Carrier EJ, Ho W-SV, Shi L, Patel S, Gorzalka BB et al (2008a). Prolonged glucocorticoid treatment decreases cannabinoid CB1 receptor density in the hippocampus. Hippocampus 18: 221-226. 
Hill MN, Miller GE, Ho W-S V, Gorzalka BB, Hillard CJ (2008b). Serum endocannabinoid content is altered in females with depressive disorders: a preliminary report. Pharmacopsychiatry 41: 48-53.

Hofmann SG (2007). Enhancing exposure-based therapy from a translational research perspective. Behav Res Ther 45: 1987-2001.

Holmes A, Singewald N (2013). Individual differences in recovery from traumatic fear. Trends Neurosci 36: 23-31.

Hoskins M, Pearce J, Bethell A, Dankova L, Barbui C, Tol WA et al (2015). Pharmacotherapy for post-traumatic stress disorder: systematic review and meta-analysis. $\mathrm{Br} J$ Psychiatry 206: 93-100.

Järbe TUC, DiPatrizio N V, Li C, Makriyannis A (2007). Effects of AM1346, a high-affinity CB1 receptor selective anandamide analog, on open-field behavior in rats. Behav Pharmacol 18: 673-680.

Jetly R, Heber A, Fraser G, Boisvert D (2015). The efficacy of nabilone, a synthetic cannabinoid, in the treatment of PTSDassociated nightmares: a preliminary randomized, double-blind, placebo-controlled cross-over design study. Psychoneuroendocrinology 51: 585-588.

Kano M, Ohno-Shosaku T, Hashimotodani Y, Uchigashima M, Watanabe M (2009). Endocannabinoid-mediated control of synaptic transmission. Physiol Rev 89: 309-380.

Kathuria S, Gaetani S, Fegley D, Valiño F, Duranti A, Tontini A et al (2003). Modulation of anxiety through blockade of anandamide hydrolysis. Nat Med 9: 76-81.

Korem N, Akirav I (2014). Cannabinoids prevent the effects of a footshock followed by situational reminders on emotional processing. Neuropsychopharmacology 39: 2709-2722.

Long JZ, Li W, Booker L, Burston JJ, Kinsey SG, Schlosburg JE et al (2009). Selective blockade of 2-arachidonoylglycerol hydrolysis produces cannabinoid behavioral effects. Nat Chem Biol 5: 37-44.

Manduca A, Lassalle O, Sepers M, Campolongo P, Cuomo V, Marsicano $G$ et al (2016). Interacting cannabinoid and opioid receptors in the nucleus accumbens core control adolescent social play. Front Behav Neurosci 10: 211.

Manduca A, Morena M, Campolongo P, Servadio M, Palmery M, Trabace L et al (2015). Distinct roles of the endocannabinoids anandamide and 2-arachidonoylglycerol in social behavior and emotionality at different developmental ages in rats. Eur Neuropsychopharmacol 25: 1362-1374.

Marsicano G, Wotjak CT, Azad SC, Bisogno T, Rammes G, Cascio MG et al (2002). The endogenous cannabinoid system controls extinction of aversive memories. Nature 418: 530-534.

Matsuda S, Matsuzawa D, Ishii D, Tomizawa H, Shimizu E (2014). Effects of memory age and interval of fear extinction sessions on contextual fear extinction. Neurosci Lett 578: 139-142.

McGuire JF, Lewin AB, Storch EA (2014). Enhancing exposure therapy for anxiety disorders, obsessive-compulsive disorder and post-traumatic stress disorder. Expert Rev Neurother 14: 893-910.

Micale V, Stepan J, Jurik A, Pamplona FA, Marsch R, Drago F et al (2017). Extinction of avoidance behavior by safety learning depends on endocannabinoid signaling in the hippocampus. J Psychiatr Res 90: 46-59.

Milad MR, Quirk GJ (2012). Fear extinction as a model for translational neuroscience: ten years of progress. Annu Rev Psychol 63: $129-151$

Moore SA (2009). Cognitive abnormalities in posttraumatic stress disorder. Curr Opin Psychiatry 22: 19-24.
Morena M, Campolongo P (2014). The endocannabinoid system: An emotional buffer in the modulation of memory function. Neurobiol Learn Mem 112: 30-43.

Morena M, De Castro V, Gray JM, Palmery M, Trezza V, Roozendaal B et al (2015). Training-associated emotional arousal shapes endocannabinoid modulation of spatial memory retrieval in rats. J Neurosci 35: 13962-13974.

Morena M, Leitl KD, Vecchiarelli HA, Gray JM, Campolongo P, Hill MN (2016a). Emotional arousal state influences the ability of amygdalar endocannabinoid signaling to modulate anxiety. Neuropharmacology 111: 59-69.

Morena M, Patel S, Bains JS, Hill MN (2016b). Neurobiological interactions between stress and the endocannabinoid system. Neuropsychopharmacology 41: 80-102.

Pamplona FA, Bitencourt RM, Takahashi RN (2008). Short- and long-term effects of cannabinoids on the extinction of contextual fear memory in rats. Neurobiol Learn Mem 90: 290-293.

Parsons RG, Ressler KJ (2013). Implications of memory modulation for post-traumatic stress and fear disorders. Nat Neurosci 16: 146-153.

Piomelli D, Tarzia G, Duranti A, Tontini A, Mor M, Compton TR et al (2006). Pharmacological profile of the selective FAAH inhibitor KDS-4103 (URB597). CNS Drug Rev 12: 21-38.

Qi M, Morena M, Vecchiarelli HA, Hill MN, Schriemer DC (2015). A robust capillary liquid chromatography/tandem mass spectrometry method for quantitation of neuromodulatory endocannabinoids. Rapid Commun Mass Spectrom 29: 1889-1897.

Quirk GJ, Paré D, Richardson R, Herry C, Monfils MH, Schiller D et al (2010). Erasing fear memories with extinction training. J Neurosci 30: 14993-14997.

Rabinak CA, Phan KL (2014). Cannabinoid modulation of fear extinction brain circuits: a novel target to advance anxiety treatment. Curr Pharm Des 20: 2212-2217.

Robinson L, Hinder L, Pertwee RG, Riedel G (2003). Effects of delta9-THC and WIN-55,212-2 on place preference in the water maze in rats. Psychopharmacology (Berl) 166: 40-50.

Sciolino NR, Zhou W, Hohmann AG (2011). Enhancement of endocannabinoid signaling with JZL184, an inhibitor of the 2 -arachidonoylglycerol hydrolyzing enzyme monoacylglycerol lipase, produces anxiolytic effects under conditions of high environmental aversiveness in rats. Pharmacol Res 64: 226-234.

Shoshan N, Segev A, Abush H, Mizrachi Zer-Aviv T, Akirav I (2017). Cannabinoids prevent the differential long-term effects of exposure to severe stress on hippocampal- and amygdaladependent memory and plasticity. Hippocampus 27: 1093-1109.

Singewald N, Schmuckermair C, Whittle N, Holmes A, Ressler KJ (2015). Pharmacology of cognitive enhancers for exposure-based therapy of fear, anxiety and trauma-related disorders. Pharmacol Ther 149: 150-190.

Trezza V, Campolongo P (2013). The endocannabinoid system as a possible target to treat both the cognitive and emotional features of post-traumatic stress disorder (PTSD). Front Behav Neurosci 7: 100.

Wang M, Hill MN, Zhang L, Gorzalka BB, Hillard CJ, Alger BE (2012). Acute restraint stress enhances hippocampal endocannabinoid function via glucocorticoid receptor activation. J Psychopharmacol 26: 56-70.

Wheeler AL, Teixeira CM, Wang AH, Xiong X, Kovacevic N, Lerch JP et al (2013). Identification of a functional connectome for longterm fear memory in mice. PLoS Comput Biol 9: e1002853. 